\title{
Influence of Rubber Composition on Mechanical Properties
}

\author{
Martin Vašina ${ }^{1}$, Marek Pöschl2,3, Petr Zádrapa ${ }^{2,3}$ \\ ${ }^{1}$ Faculty of Mechanical Engineering, VSB-Technical University of Ostrava, 17. listopadu 15/2172, 70833 Ostrava- \\ Poruba. Czech Republic. E-mail: martin.vasina@vsb.cz. \\ ${ }^{2}$ Faculty of Technology, Tomas Bata University in Zlin, Vavrečkova 275, 76001 Zlin. Czech Republic. E-mail: \\ poschl@utb.cz,zadrapa@utb.cz. \\ ${ }^{3}$ Centre of Polymer Systems, Tomas Bata University in Zlin, Tř́ída Tomáše Bati 5678, 76001 Zlin. Czech Republic. \\ E-mail: poschl@utb.cz,zadrapa@utb.cz.
}

The purpose of this contribution is to investigate different mechanical properties of various types of rubber composite materials that were filled with carbon black nanofiller. The rubber composites were produced from three different basic rubbers. Moreover, the composites were produced with different volume concentrations of the basic rubbers including their various ratios. Mechanical properties of the tested rubber composites were investigated by means of tensile testing, Shore hardness, rebound resilience, mechanical friction, abrasion, viscoelastic behaviour and vibration damping measurements. It was found in this study that the rubber composition has a significant influence on the stiffness of the investigated rubber composites, and thus, on their mechanical properties.

Keywords: Rubber Composites, Mechanical Properties, Vibration Damping, Friction, Viscoelasticity.

\section{Introduction}

Rubbers are polymers characterized by their highly reversible deformation (up to 1000\%). Generally, there are natural or synthetic rubbers. The natural rubber is obtained by cutting the bark from Hevea brasiliensis (rubber tree). A milky fluid, which is called as latex, flows from the tree. Subsequently, it is necessary to precipitate the latex with either acetic acid or hydrochloric acid. The resulting lumps are subsequently washed, dried and compressed into bales for the purpose of their export and further processing [1]. The natural rubber is frequently used in rubber industry. Nevertheless, the rubber is characterized by low heat resistance and wide distribution curve (i.e. chains of different lengths in a system). Therefore, the natural rubber is used in combination with synthetic rubbers due to its temperature resistance. Synthetic rubbers are manufactured by emulsion polymerization in a reactor. There are different types of synthetic rubbers, e.g. rubbers for general applications (e.g. SBR-Styrenebutadiene rubber, BR-butadiene rubber and IRisopren rubber) and other purposes (e.g. EPM, EPDM, CR and NBR rubbers) [1, 2]. Mixtures of natural and synthetic elastomers are used too. The combination of NR/BR rubbers is often used for dynamically stressed products (e.g. tires). The BR rubber is characterized by low glass transition temperature and low abrasion resistance. The rubber product with the addition of BR rubber can thus be used at low temperatures [3]. Because the rubbers haven't required pro- perties (e.g. plasticity and ductility), they aren't individually used in practice. Therefore, there are added different ingredients (fillers, vulcanization agents, UV stabilizers etc.) to these rubbers. A rubber mixture composition is expressed in phr units (i.e. parts by weight, per 100 parts of rubber). If the rubber mixture is heated to high temperatures, the crosslinking process occurs and the rubber mixture is changed into elastic rubber, i.e. vulcanizate [2, 4]. The vulcanization is defined as a chemical reaction of a vulcanizer agent with elastomer chains. After vulcanization, the linear molecules are crosslinked and a network is formed [5]. Sulphur and peroxides are the most frequently used as the vulcanizer agents. The advantage of sulphur is its low price and easy availability. Nevertheless, sulphur is characterized by a low temperature resistance. In order to ensure a higher temperature resistance, it is necessary to apply peroxides for these purposes. During the sulphur vulcanization, C-Sn-C polysulfide bonds are formed. These bonds have lower bond energy compared to the peroxide vulcanization that is characterized by C-C bonds, which are stiffer compared to the polysulfide bonds. For this reason, the peroxidevulcanized rubbers are more resistant to heat $[2,4,6]$.

Rubber products are widely used in different applications, e.g. as tires, hoses, static and dynamic seals, gas masks, conveyor belts, rubber boots and vibro-insulation damping elements [7]. Different types of fillers are applied in rubber mixtures in order to improve their physical and mechanical properties and to reduce their production costs. Generally, the fillers are divided according to the filler primary particle size (i.e. 
active and semi active fillers), their colour origin (i.e. natural or synthetic) and the shape of primary particles. At the present time, there are applied different types of nanofillers. Carbon black belongs to the most frequently used fillers in rubber industry. The stiffening effect depends mainly on the size of the primary particles and the surface activity of the filler. Generally, the stiffening effect increases with the decreasing specific surface area of the filler. Various functional groups on the filler surface can influence the stiffening effect. Good mechanical properties can be obtained with light fillers [7-11].

\section{Experimental}

\subsection{Investigated materials}

The designation and composition of the rubber mixtures, which were investigated in this work, are shown in Tab. 1. Styrene-butadiene rubber of SBR1500 type (Synthos Kralupy a.s., Kralupy nad Vltavou, Czech Republic) containing 23.5\% styrene (designated as SBR), Buna CB 25 butadiene rubber (designated as BR) and STR-20 natural rubber (Standard Thaisian Rubber) with a low content of impurities (designated as NR) were used as the basic components of the produced rubber mixtures. The rubber mixtures were filled by carbon black N 320 nanofiller (CS CABOT Ltd., Valašské Meziř́ící, Czech Republic), vulcanization activators (i.e. stearin and zinc oxide $\mathrm{ZnO}$ ), vulcanization accelerator TBBS (i.e. N-t-butyl-2-benzothiazole sulfenamide) and sulphur, as shown in Tab. 1. The used carbon black $N 320$ nanofiller consists of the particles measuring $(0.026 \div 0.030) \mu \mathrm{m}$ in the diameter and is applied in order to absorb ultraviolet radiation $[12,13]$.

Tab. 1 Designation and composition (in phr units) of the tested rubber mixtures

\begin{tabular}{|c|c|c|c|c|c|c|}
\hline \multirow{2}{*}{ Ingredient type } & \multicolumn{7}{|c|}{ Rubber mixture designation } \\
\cline { 2 - 7 } & SBR & BR & NR & SBR/BR & SBR/NR & NR/SBR \\
\hline SBR & 100 & 0 & 0 & 70 & 70 & 30 \\
\hline BR & 0 & 100 & 0 & 30 & 0 & 0 \\
\hline NR & 0 & 0 & 100 & 0 & 30 & 70 \\
\hline N 320 & 50 & 50 & 50 & 50 & 50 & 50 \\
\hline ZnO & 3 & 3 & 3 & 3 & 3 & 3 \\
\hline Stearin & 1 & 1 & 1 & 1 & 1 & 1 \\
\hline TBBS & 1 & 1 & 1 & 1 & 1 & 1 \\
\hline Sulphur & 1.75 & 1.75 & 1.75 & 1.75 & 1.75 & 1.75 \\
\hline
\end{tabular}

The rubber mixtures were produced by two-stage mixing. The time record of the rubber mixing process is described in Tab. 2. The first stage was realized on a Pommini Farrel kneader at the temperature of $70{ }^{\circ} \mathrm{C}$ and at the speed of $99 \mathrm{rev} / \mathrm{min}$. After this immixture, the mixture was drained out from the Pommini Farrel kneader. Subsequently, vulcanization accelerator TBBS and sulphur were added to the mixture on a Farrel double roller. The second stage was performed at the temperature of $60^{\circ} \mathrm{C}$ and at the speed ratio of $12 / 15$ of both rollers. After this mixing process, the rubber mixture was stored for its further processing for a period of 24 hours at the ambient temperature of $22{ }^{\circ} \mathrm{C}$. Rubber samples were subsequently pressed from the produced rubber mixtures at the temperature of $165^{\circ} \mathrm{C}$ in order to investigate their mechanical properties.

Tab. 2 Time record of rubber mixing process

\begin{tabular}{|c|c|c|}
\hline Mixing equipment & $\begin{array}{c}\text { Sequence of additive } \\
\text { feeding }\end{array}$ & Adding time (min) \\
\hline \multirow{4}{*}{$\begin{array}{c}\text { Pommini Farrel } \\
\text { kneader }\end{array}$} & $\begin{array}{c}\text { Basic rubber type } \\
\text { (SBR, BR or NR) }\end{array}$ & $0: 00$ \\
\cline { 2 - 3 } & ZnO + stearin & $1: 00$ \\
\cline { 2 - 3 } & $1^{\text {st }}$ half of N 320 & $2: 00$ \\
\cline { 2 - 3 } & $2^{\text {nd }}$ half of N 320 & $3: 00$ \\
\hline \multirow{3}{*}{ Farrel double roller } & Batch drainage & $8: 00$ \\
\cline { 2 - 3 } & Mixture from 1st stage & $0: 00$ \\
\cline { 2 - 3 } & TBBS + sulphur & $7: 00$ \\
\hline
\end{tabular}




\subsection{Measurement methodology}

Tensile tests were performed on a T10D tensile testing machine from Alpha Technology according to ISO 37 standard at the ambient temperature of $23^{\circ} \mathrm{C}$. In this case, eight samples of the given rubber type (see Tab. 1) measuring $2 \mathrm{~mm}$ in thickness were strained at the test speed of $50 \mathrm{~mm} / \mathrm{min}$. Average values of measured quantities and their standard deviations were subsequently evaluated.

The Shore A hardness was measured according to ISO 7619 standard at the ambient temperature of 22 ${ }^{\circ} \mathrm{C}$. Samples of the given rubber type measuring $6 \mathrm{~mm}$ in thickness were tested and the parameters (i.e., median and arithmetic average) were obtained from five measured values.

The rebound resilience was realized according to ISO 4662 standard. Three rubber specimens measuring $6 \mathrm{~mm}$ in thickness were examined at the ambient temperature of $22^{\circ} \mathrm{C}$. Subsequently, the average value of the rebound resilience and its standard deviation were determined.

Mechanical friction between two surfaces is characterized by transformation of kinetic energy into heat and is defined as the resistance to movement. It consisted in measurement of the static $\left(\mu_{s}\right)$ and kinetic $\left(\mu_{k}\right)$ coefficients between rubber and a plastic surface by means of the FS-5N digital force gauge (from Imada CO, Toyohashi, Japan). In the case of solid-onsolid friction, these friction coefficients are defined as follows [14]:

$$
\begin{aligned}
& \mu_{s}=\frac{F_{s}}{P}[-], \\
& \mu_{k}=\frac{F_{k}}{P}[-],
\end{aligned}
$$

Where:

$\mathrm{F}_{\mathrm{s}}$...Force just sufficient to prevent the relative motion between two bodies $[\mathrm{N}]$,

$\mathrm{F}_{\mathrm{k}}$...Force needed to maintain relative motion between two bodies [N],

P...Force normal to the interface between the sliding bodies [N].

The measurements of the friction coefficients were performed on rubber samples measuring $20 \mathrm{~mm}$ in thickness and $100 \mathrm{~mm}$ in diameter and for two inertial masses $m$ (i.e., 0 and $250 \mathrm{~g}$ ), which were placed on the upper side of the tested samples. The kinetic coefficient was evaluated at the sliding velocity of approx. $0.1 \mathrm{~m} / \mathrm{s}$. Average values of the static and kinetic coefficients and their standard deviations were subsequently evaluated from ten measured values. The measurements were realized at the ambient temperature of $23^{\circ} \mathrm{C}$.
The abrasion measurement was performed according to ČSN 621466 standard by means of BussenSchlobach method. This method is based on the exposure of a cylindrical specimen to an abrasive medium. The test apparatus consisted of a rotating cylinder and a slider in which the specimen was clamped. The surface of the rotating cylinder was equipped with an abrasive paper. The slider was mounted on a pendulum allowing a longitudinal movement of the tested samples on the rotating cylinder. The samples were tested on a total abrasion path of approx. $50 \mathrm{~m}$ under a pressure force of $10 \mathrm{~N}$. Abrasion properties of the tested rubber samples were evaluated by the relative weight loss $W_{i}$ :

$$
W_{r}=\frac{W_{1}-W_{2}}{W_{1}} \cdot 100[\%],
$$

\section{Where:}

$\mathrm{W}_{1}$...Sample weight before abrasion $[\mathrm{kg}]$,

$\mathrm{W}_{2}$...Sample weight after abrasion $[\mathrm{kg}]$.

The rubber abrasion increases with an increase in the relative weight loss $W_{r}$. Experimental measurements were realized on rubber samples measuring 16 $\mathrm{mm}$ in diameter and $6 \div 12 \mathrm{~mm}$ in thickness at the ambient temperature of $24^{\circ} \mathrm{C}$. Average values of the relative weight loss and their standard deviations were evaluated from three measured values.

Dynamical mechanical analysis (DMA) was performed on Mettler Toledo DMA 1 equipment in tensile mode for the tested rubber specimens whose geometrical dimensions were $10 \times 5 \times 1 \mathrm{~mm}$ (length $\times$ width $\times$ thickness). Viscoelastic parameters (i.e., storage modulus $E$ ', loss modulus $E$ " and loss factor $\tan \delta$ ) were determined in the temperature sweep from $-130{ }^{\circ} \mathrm{C}$ to $25^{\circ} \mathrm{C}$ at the constant deformation of $5 \mu \mathrm{m}$ and at the excitation frequency of $1 \mathrm{~Hz}$.

Rubber process analysis (RPA) was realized on Premier RPA analyser in shear mode for the tested rubber specimens. Viscoelastic parameters (i.e., storage modulus $G^{\prime}$, loss modulus $G^{\prime \prime}$ and loss factor $\tan \delta$ ) were determined in two different ways. Firstly, the frequency sweep was measured at the constant deformation amplitude of $2 \%$ (proportional to the angular displacement amplitude of $0.14^{\circ}$ ) with the varying frequency from 0 to $50 \mathrm{~Hz}$. Secondly, the strain sweep was investigated with the varying sample deformation amplitude from 0 to $70 \%$ (proportional to the angular displacement amplitude from 0 to $5^{\circ}$ ) at two excitation frequencies (i.e., 1 and $5 \mathrm{~Hz}$ ) and two temperatures (i.e., 50 and $80^{\circ} \mathrm{C}$ ).

Vibration damping properties of the investigated rubber composites were performed by the forced oscillation method using a BK 4810 (Brüel \& Kjær, Nærum, Denmark) mini-shaker in combination with a BK 3560-B-030 signal pulse multi-analyzer and a BK 
2706 power amplifier at the frequency range of $2 \div 1500 \mathrm{~Hz}$. The material's ability to dampen harmonically excited vibrations for the basic linear single-degree-of-freedom system is expressed by the displacement transmissibility $T_{d}[15,16]$, which is in the case of the harmonically excited vibrations defined by the formula (4):

$$
T_{d}=\frac{X}{Y}=\frac{A_{X}}{A_{Y}}=\sqrt{\frac{1+(2 \zeta \cdot r)^{2}}{\left(1-r^{2}\right)^{2}+(2 \zeta \cdot r)^{2}}}[-]
$$

Where:

$\mathrm{X}$...Displacement amplitude of the response [m],

Y...Displacement amplitude of the base [m],

Ax...Acceleration amplitude of the response $\left[\mathrm{m} / \mathrm{s}^{2}\right]$,

$A_{Y}$...Acceleration amplitude of the base $\left[\mathrm{m} / \mathrm{s}^{2}\right]$,

$\zeta$...Damping ratio $[-]$,

r...Frequency ratio $[-]$, which is defined by the equation (5):

$$
r=\frac{\omega}{\omega_{n}}=\frac{\omega}{\sqrt{k / m}}=\frac{2 \pi \cdot f}{\sqrt{k / m}}[-],
$$

Where:

$\omega . .$. Frequency of forced oscillation $\left[\mathrm{rad} \cdot \mathrm{s}^{-1}\right]$,

$\omega_{\mathrm{n}} \ldots$ Undamped natural frequency $\left[\mathrm{rad} \cdot \mathrm{s}^{-1}\right]$,

f...Frequency $[\mathrm{Hz}]$,

$\mathrm{k}$...Stiffness $\left[\mathrm{N} \cdot \mathrm{m}^{-1}\right]$,

m...Mass $[\mathrm{kg}]$.

Mechanical vibrations are the source of noise [17]. Based on the value of the displacement transmissibility, there are generally three different types of mechanical vibration, i.e. resonance $\left(T_{d}>1\right)$, undamped $\left(T_{d}\right.$ $=1)$ and damped $\left(T_{d}<1\right)$ vibration. Under the condition $d T_{d} / d r=0$ in the equation (4), it is possible to find the local extreme of the displacement transmissibility $T_{d m a x}$ at the frequency ratio $r_{0}$ [15]:

$$
r_{0}=\frac{\sqrt{\sqrt{1+8 \zeta^{2}}-1}}{2 \zeta}[-] \text {. }
$$

It is evident from the above-mentioned equation that the maximum value of the displacement transmissibility is generally shifted to lower values of the frequency ratio $r$ with an increase in the damping ratio $\zeta$ (or with a decrease in the stiffness $k$ ). The acceleration amplitudes $A_{X}$ and $A_{Y}$ were recorded by BK 4393 (Brüel \& Kjær, Nærum, Denmark) accelerometers. Measurements of the displacement transmissibility were performed for different inertial masses $m$ (i.e., 160 and $305 \mathrm{~g}$ ), which were placed on the upper side of the harmonically loaded rubber samples. Furthermore, vibration damping properties of the tested rubber samples with the ground plane dimensions $60 \times 60$ $\mathrm{mm}$ were performed for two different material thicknesses (i.e., 10 and $20 \mathrm{~mm}$ ). Each measurement was repeated 5 times at the ambient temperature of $22^{\circ} \mathrm{C}$.

\section{Measured results and discussion}

Basic mechanical properties (namely the modulus of elasticity $E_{50}$ at $50 \%$ sample extension, the Shore A hardness and the rebound resilience $R$ ) of the tested rubber specimens are shown in Tab. 3. It is evident that the lowest values of the hardness and the rebound resilience and the highest values of the modulus $E_{50}$ were found for the samples that were produced with a higher content of the SBR rubber. Contrariwise, the samples produced with a higher content of the NR and BR rubbers showed lower values of the modulus of elasticity and higher values of the hardness and the rebound resilience (see Tab. 3).

The experimentally obtained values of the static $\left(\mu_{s}\right)$ and kinetic $\left(\mu_{k}\right)$ coefficients between the tested rubber surfaces and a plastic material for two different inertial masses $(m)$ are shown in Tab. 4. It was found that higher values of the friction coefficients were generally obtained for harder rubber samples (i.e., NR type). On the contrary, the softest SBR rubber type embodied the lowest mechanical friction. It is visible (see Tab. 4) that the higher inertial mass $m$ led to higher values of the friction coefficients. It was caused by a higher acting pressure force on the plastic material, and thus, by a higher resistance to rubber motion. It was also verified that the static friction coefficient is higher than the kinetic friction coefficient [18].

Tab. 3 Basic mechanical properties of the investigated rubber samples

\begin{tabular}{|c|c|c|c|}
\hline Rubber sample & $\begin{array}{c}\mathrm{E}_{50} \\
{[\mathrm{MPa}]}\end{array}$ & $\begin{array}{c}\text { Shore A } \\
{[\mathrm{Sh} \mathrm{A}]}\end{array}$ & $\begin{array}{c}\mathrm{R} \\
{[\%]}\end{array}$ \\
\hline SBR & $1.62 \pm 0.10$ & $61 \pm 1$ & $34 \pm 1$ \\
\hline BR & $1.58 \pm 0.06$ & $64 \pm 1$ & $54 \pm 1$ \\
\hline NR & $1.38 \pm 0.09$ & $65 \pm 1$ & $50 \pm 1$ \\
\hline SBR/BR & $1.67 \pm 0.09$ & $65 \pm 1$ & $46 \pm 1$ \\
\hline SBR/NR & $1.63 \pm 0.17$ & $62 \pm 1$ & $37 \pm 1$ \\
\hline NR/SBR & $1.38 \pm 0.07$ & $65 \pm 1$ & $45 \pm 1$ \\
\hline
\end{tabular}


Tab. 4 Measured values of the friction coefficients between a plastic material and the tested rubber samples

\begin{tabular}{|c|c|c|c|}
\hline \multirow{2}{*}{ Rubber sample } & $\mathrm{m}$ & $\mu_{\mathrm{s}}$ & $\mu_{\mathrm{k}}$ \\
& {$[\mathrm{g}]$} & {$[-]$} & {$[-]$} \\
\hline \multirow{2}{*}{$\mathrm{SBR}$} & 0 & $0.54 \pm 0.04$ & $0.38 \pm 0.01$ \\
\cline { 2 - 4 } & 250 & $0.80 \pm 0.06$ & $0.58 \pm 0.04$ \\
\hline \multirow{2}{*}{$\mathrm{BR}$} & 0 & $0.81 \pm 0.08$ & $0.62 \pm 0.06$ \\
\cline { 2 - 4 } & 250 & $0.86 \pm 0.07$ & $0.74 \pm 0.07$ \\
\hline \multirow{2}{*}{$\mathrm{NR}$} & 0 & $0.95 \pm 0.09$ & $0.79 \pm 0.07$ \\
\cline { 2 - 4 } & 250 & $1.05 \pm 0.09$ & $0.84 \pm 0.05$ \\
\hline \multirow{2}{*}{ SBR/BR } & 0 & $0.64 \pm 0.06$ & $0.53 \pm 0.03$ \\
\cline { 2 - 4 } & 250 & $0.84 \pm 0.07$ & $0.59 \pm 0.05$ \\
\hline \multirow{2}{*}{ SBR/NR } & 0 & $0.76 \pm 0.05$ & $0.61 \pm 0.02$ \\
\cline { 2 - 4 } & 250 & $0.91 \pm 0.06$ & $0.62 \pm 0.06$ \\
\hline \multirow{2}{*}{$\mathrm{NR} / \mathrm{SBR}$} & 0 & $0.83 \pm 0.04$ & $0.65 \pm 0.06$ \\
\cline { 2 - 4 } & 250 & $0.94 \pm 0.06$ & $0.70 \pm 0.06$ \\
\hline
\end{tabular}

As shown in Tab. 5, the rubber composition has a big influence on its abrasion too. It is evident that a higher abrasion (or a higher relative weight loss $W_{r}$ ) after the abrasion process was observed for the NR rubber sample (incl. its mixtures). On the contrary, the BR rubber type exhibited the lowest abrasion resistance.

Tab. 5 Results of the abrasion testing for the investigated rubber samples

\begin{tabular}{|c|c|c|c|}
\hline Rubber sample & $\begin{array}{c}\mathrm{W}_{1} \\
{[\mathrm{~g}]}\end{array}$ & $\begin{array}{c}\mathrm{W}_{2} \\
{[\mathrm{~g}]}\end{array}$ & $\begin{array}{c}\mathrm{W}_{\mathrm{r}} \\
{[\%]}\end{array}$ \\
\hline SBR & $1.98 \pm 0.02$ & $1.90 \pm 0.02$ & $4.19 \pm 0.23$ \\
\hline BR & $1.92 \pm 0.03$ & $1.90 \pm 0.03$ & $1.14 \pm 0.25$ \\
\hline NR & $1.90 \pm 0.02$ & $1.78 \pm 0.03$ & $6.19 \pm 0.24$ \\
\hline SBR/BR & $1.95 \pm 0.03$ & $1.88 \pm 0.03$ & $3.34 \pm 0.19$ \\
\hline SBR/NR & $2.01 \pm 0.02$ & $1.91 \pm 0.02$ & $4.65 \pm 0.01$ \\
\hline NR/SBR & $1.93 \pm 0.01$ & $1.82 \pm 0.01$ & $5.66 \pm 0.15$ \\
\hline
\end{tabular}
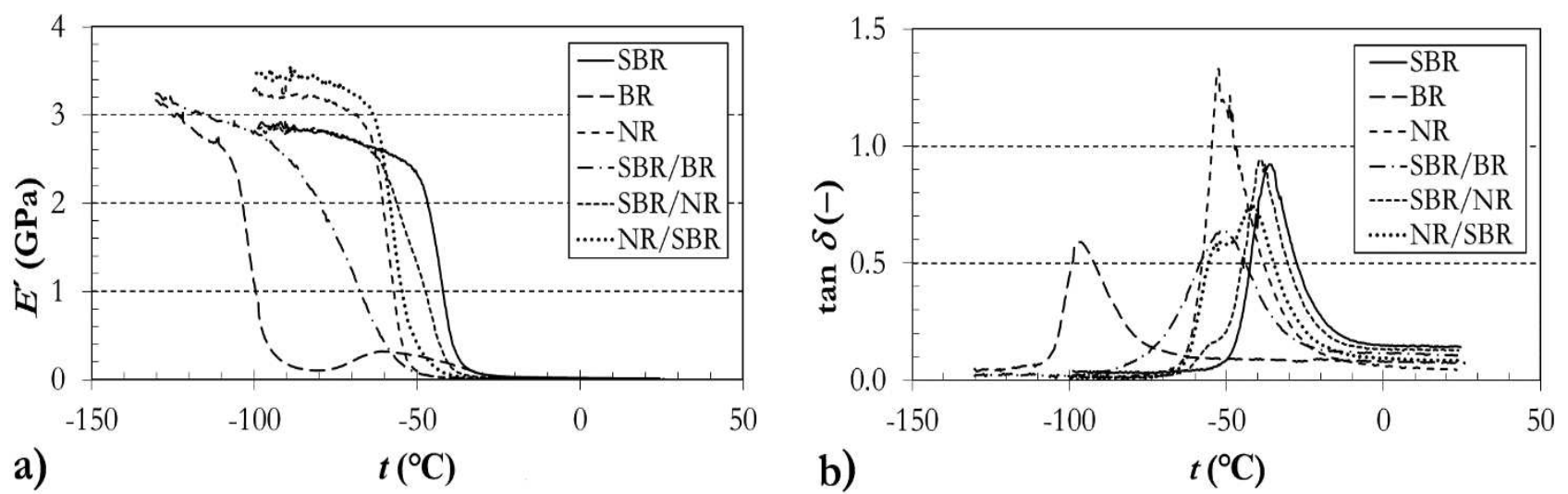

Fig. 1 Temperature dependencies of the tensile storage modulus (a) and the loss factor (b) of the tested rubber samples at the sample deformation $x=5 \mu \mathrm{m}$ and the frequency $f=1 \mathrm{~Hz}$

The tested rubber composites were subsequently investigated in terms of their viscoelastic behaviour. The storage modulus, the loss modulus and the loss factor [19] were investigated in the tensile and shear modes.

Temperature dependencies of the storage modulus $E^{\prime}$ and the loss factor $\tan \delta$ in the tensile mode of the investigated rubber samples at the sample deformation $x=5 \mu \mathrm{m}$ and the excitation frequency $f=1 \mathrm{~Hz}$ are shown in Fig. 1. It is evident that the storage modulus decreased with an increase in the operating temperature. A lower stiffness (i.e. a decrease of the storage modulus at lower temperatures) was observed for the BR sample type, incl. the SBR/BR mixture. On the 
contrary, the SBR and NR rubber samples (incl. their mixtures) are characterized by a higher stiffness, namely at higher temperatures (see Fig. 1a). It is also visible (see Fig. 1b) that the BR and SBR/BR samples exhibited generally higher values of the loss factor at lower operating temperatures (in this case at $t<-60$

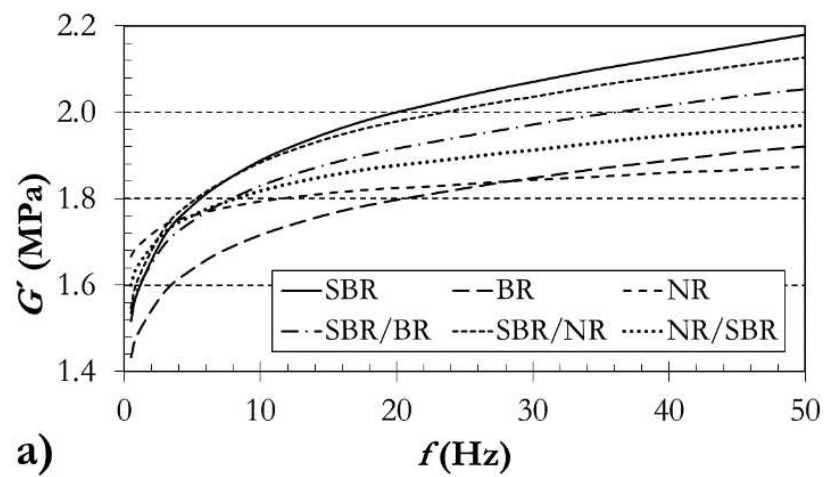

$\left.{ }^{\circ} \mathrm{C}\right)$. Therefore, the rubber samples containing the basic BR rubber achieve better damping properties (or a higher transformation of input mechanical energy into heat under dynamic loading) at lower operating temperatures. Contrariwise, the SBR and NR rubber samples and their composites exhibited better damping properties at higher operating temperatures.

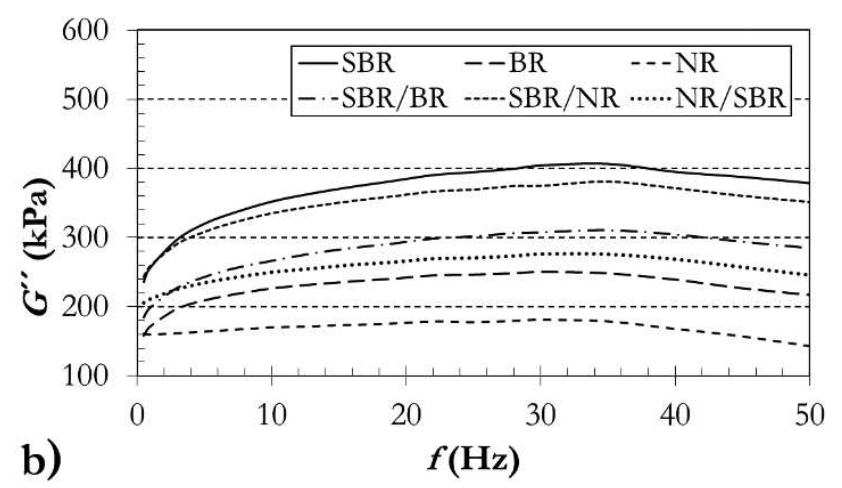

Fig. 2 Frequency dependencies of the shear storage modulus (a) and the shear loss modulus (b) of the tested rubber samples at the sample deformation amplitude $x=2 \%$ and the temperature $t=50{ }^{\circ} \mathrm{C}$

Viscoelastic properties of the investigated rubber composites were also determined by means of the RPA measurements in the shear mode. Fig. 2 illustrates frequency dependencies of the shear storage and loss moduli of the tested rubber samples at the operating temperature of $50{ }^{\circ} \mathrm{C}$ and the deformation amplitude of $2 \%$. It is evident that the shear storage modulus $G^{\prime}$ increased with an increase in the excitation frequency (see Fig. 2a). It is also visible that the rubber composites containing the SBR rubber type are characterized by a higher stiffness compared to the BR and NR rubbers. Similar results were also obtained for the shear loss modulus of the elasticity $G^{\prime \prime}$ (see Fig.

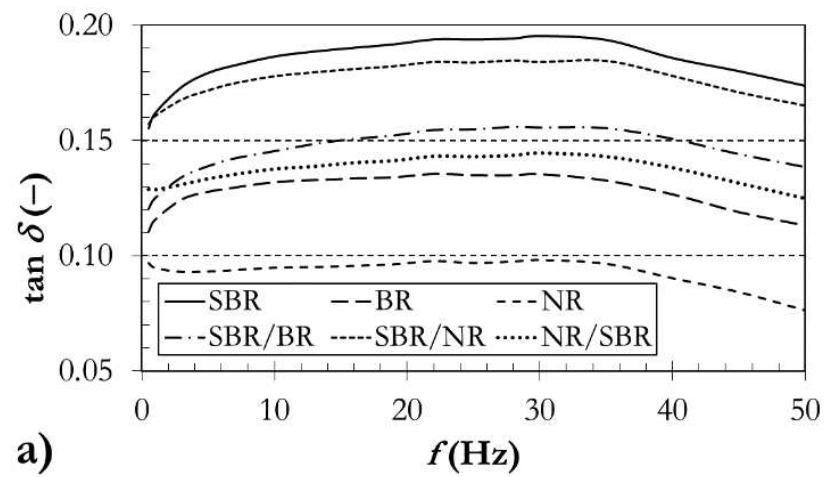

2b). Nevertheless, the highest values of the shear loss modulus were observed at the excitation frequency $f \cong$ $33 \mathrm{~Hz}$.

Frequency dependencies of the loss factor $\tan \delta$ at the deformation amplitude of $2 \%$ for two different operating temperatures (i.e., $50{ }^{\circ} \mathrm{C}$ and $80{ }^{\circ} \mathrm{C}$ ) are shown in Fig. 3. They correspond with the obtained results of the shear loss modulus of the elasticity $G^{\prime \prime}$, as shown in Fig. 2b. It was also found that the higher operating temperature (i.e., $80{ }^{\circ} \mathrm{C}$ ) resulted in lower damping properties of the tested rubber samples.

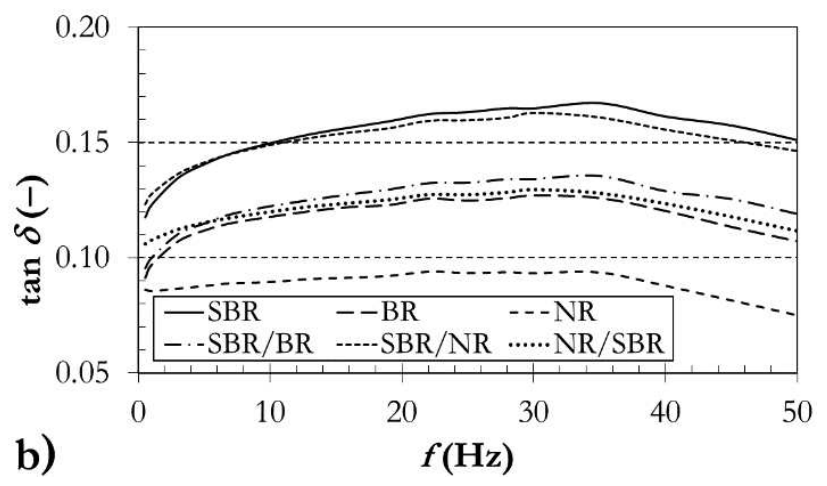

Fig. 3 Frequency dependencies of the loss factor of the tested rubber samples at the sample deformation amplitude $x=2 \%$ and the temperatures: $t=50^{\circ} \mathrm{C}$ (a) and $t=80^{\circ} \mathrm{C}(b)$.

Viscoelastic properties of the investigated rubber composites were also investigated by means of the RPA measurements in the shear mode depending on the strain amplitude. Fig. 4 demonstrates strain dependencies of the loss factor at two different operation temperatures (i.e., $50{ }^{\circ} \mathrm{C}$ and $80{ }^{\circ} \mathrm{C}$ ) at the frequency of $1 \mathrm{~Hz}$. It is evident that the lowest damping properties were obtained for the NR rubber type independently on the operating temperature. It is obvious that damping properties are significantly influenced by the strain amplitude. In the case of small sample deformations (at approx. $x<22 \%$ ), better damping properties were obtained for the rubber samples containing the 
basic SBR rubber. On the contrary, the BR rubber sample exhibited the best damping ability at higher sample deformations (at approx. $x>22 \%$ ). It is also visible that the operating temperature has a significant

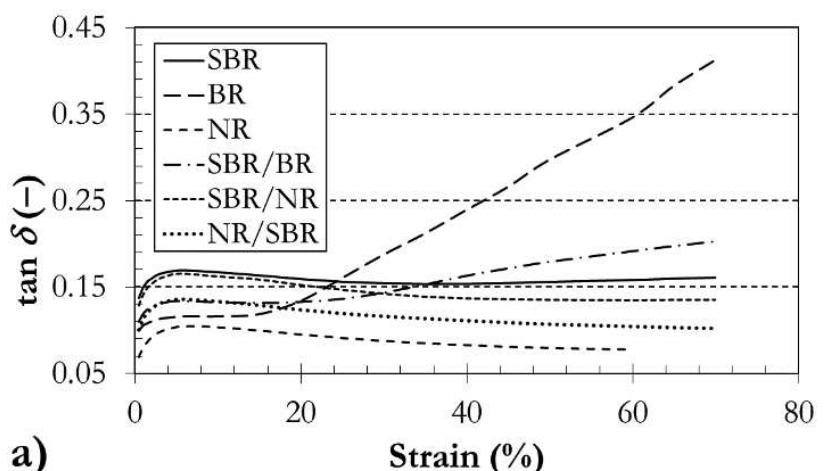

influence on damping properties of the tested rubber samples under dynamic loading in the shear mode. Generally, a positive effect of the operating temperature on the loss factor was found at higher sample deformations (see Fig. 4).

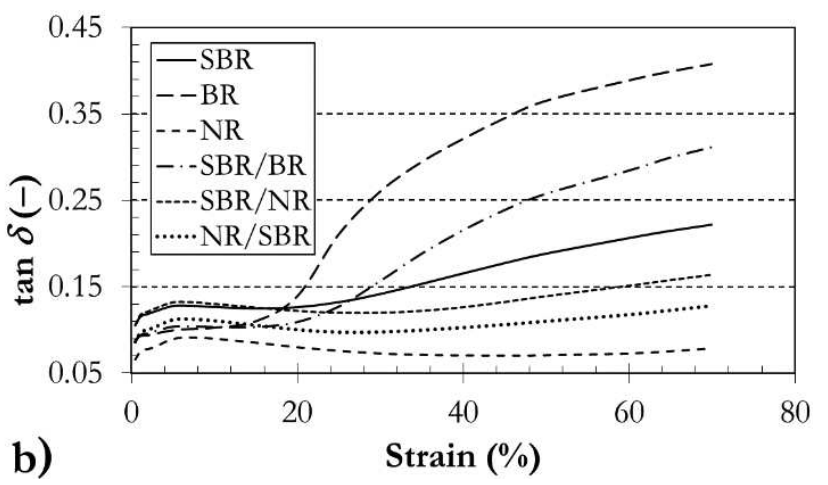

Fig. 4 Strain dependencies of the loss factor of the tested rubber samples at the excitation frequency $f=1 \mathrm{~Hz}$ and the temperatures: $t=50^{\circ} \mathrm{C}\left(\right.$ a) and $t=80^{\circ} \mathrm{C}(b)$.

The effect of the strain amplitude on the loss factor was also investigated at the excitation frequency $f=5$ $\mathrm{Hz}$ and the temperature $t=50^{\circ} \mathrm{C}$. It was found that the higher excitation frequency generally led to better damping properties of the tested rubber composites. Only in the case of the SBR/BR rubber composite, higher values of the loss factor were achieved at the excitation frequency of $1 \mathrm{~Hz}$ for higher rubber deformations (at approx. $x>30 \%$ ). It was further found in this study that strain dependencies of the shear loss modulus $G$ " were analogous to the loss factor $\tan \delta$. The shear storage modulus $G^{\prime}$ of the tested rubber samples decreased significantly with an increase in the strain amplitude.

Frequency dependencies of the displacement transmissibility of the tested rubber types are shown in Fig. 5. It is evident that the displacement transmis-

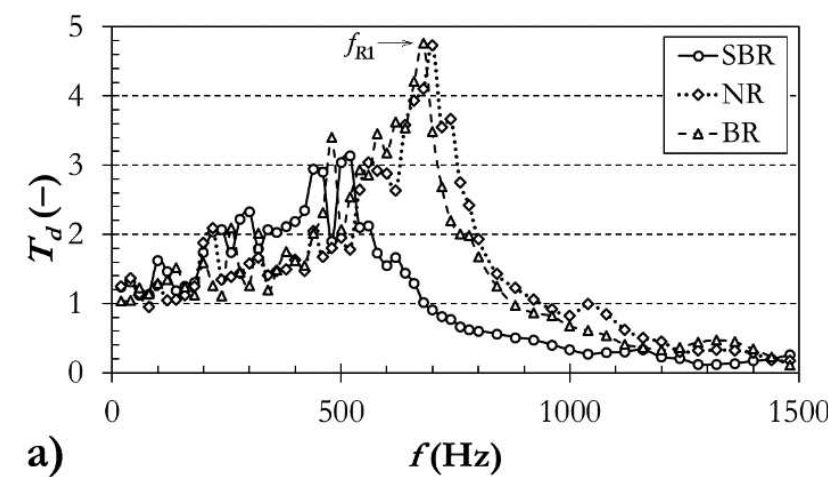

sibility is significantly influenced by the rubber composition. Better vibration damping properties $\left(T_{d}<1\right)$ were generally observed for the rubber samples containing the SBR rubber. On the contrary, the lowest vibration damping was observed for the rubber samples containing the NR rubber type, which is characterised by the highest hardness. The material's ability to damp mechanical vibration relates to the first resonance frequency $f_{R 1}$ that is proportional to the maximum value of the displacement transmissibility $T_{\text {dmax }}$. In generally, the first resonance frequency peak position is shifted to lower excitation frequencies with a decrease in the rubber stiffness. It is consistent with the equation (6). The values of the first resonance frequency $f_{R 1}$ of the studied rubber composites depending on the rubber thickness and the inertial mass are shown in Tab. 6.

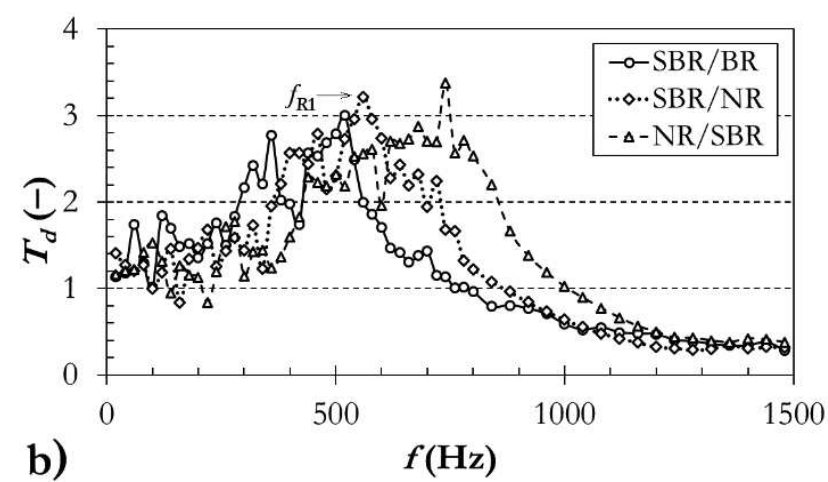

Fig. 5 Frequency dependencies of the displacement transmissibility of basic rubbers (a) and rubber composites (b) of the thickness $t=10 \mathrm{~mm}$ and loaded by the inertial mass $m=160 \mathrm{~g}$.

The effect of the inertial mass and the sample thickness on the displacement transmissibility was also investigated in this work. It was found that vibration damping properties increased with an increase in the rubber thickness and the inertial mass. This phenomenon was reflected in the decrease of the first resonance frequency peak position (see Tab. 6) to lower excitation frequencies. 
Tab. 6 First resonance frequencies $f_{R 1}$ in $\mathrm{Hz}$ of the studied rubber composites under harmonic excitation for different rubber thicknesses tand inertial masses $m$

\begin{tabular}{|l|l|l|l|}
\hline \multirow{2}{*}{ Rubber sample } & $\mathrm{t}$ & $\mathrm{m}[\mathrm{g}]$ & \\
\cline { 2 - 4 } & {$[\mathrm{mm}]$} & 160 & 305 \\
\hline \multirow{2}{*}{ SBR } & 10 & $523 \pm 18$ & $422 \pm 15$ \\
\cline { 2 - 4 } & 20 & $315 \pm 12$ & $274 \pm 11$ \\
\hline \multirow{2}{*}{ BR } & 10 & $690 \pm 26$ & $552 \pm 20$ \\
\cline { 2 - 4 } & 20 & $413 \pm 17$ & $335 \pm 15$ \\
\hline \multirow{2}{*}{ NR } & 10 & $709 \pm 31$ & $561 \pm 19$ \\
\cline { 2 - 4 } & 20 & $438 \pm 18$ & $458 \pm 17$ \\
\hline \multirow{2}{*}{ SBR/BR } & 10 & $527 \pm 23$ & $290 \pm 11$ \\
\cline { 2 - 4 } & 20 & $356 \pm 17$ & $284 \pm 16$ \\
\hline \multirow{2}{*}{ SBR/NR } & 10 & $570 \pm 17$ & $376 \pm 13$ \\
\hline \multirow{2}{*}{ NR/SBR } & 20 & $346 \pm 12$ & $347 \pm 14$ \\
\hline
\end{tabular}

It is also visible from Fig. 5 that vibration properties of the investigated rubber materials are also significantly affected by the excitation frequency. The resonance mechanical vibration $\left(T_{d}>1\right)$ was observed at low excitation frequencies depending on the rubber type, its thickness and the inertial mass. For example, for the NR/SBR rubber type of the thickness $t=$ $10 \mathrm{~mm}$ and with the inertial mass $m=160 \mathrm{~g}$ (see Fig. $5 b)$, the resonance mechanical vibration was observed at the excitation frequencies $f<1 \mathrm{kHz}$. In the case of the SBR rubber type of the thickness $t=20 \mathrm{~mm}$ and loaded with the inertial mass $m=305 \mathrm{~g}$, the resonant mechanical vibration was observed at lower excitation frequencies (at $f<350 \mathrm{~Hz}$ ). Conversely, the damped mechanical vibration $\left(T_{d}<1\right)$ was generally obtained at higher frequencies.

\section{Conclusion}

The aim of this paper was to investigate the mechanical properties of rubber composites that were filled with carbon black nanofiller and produced from three different basic rubber types. It can be stated that the mechanical properties of the investigated rubber composites are significantly affected by their composition. For this reason, it is necessary to choose a suitable rubber type for required applications. It was found in this work that the rubber composition has a strong influence on modulus of elasticity, hardness, rebound resilience, mechanical friction, abrasion, viscoelastic properties and displacement transmissibility depending on given operation conditions. Generally, softer rubber materials were characterized by lower values of rebound resilience, abrasion and mechanical friction. Furthermore, these materials exhibited better vibration damping properties, which resulted in a higher transformation of input mechanical energy into heat under harmonically excited vibration and in a decrease of the first resonance frequency.

\section{Acknowledgements}

This work was supported by Research Centre of Advanced Mechatronic Systems project, project number CZ.02.1.01/0.0/0.0/16_019/0000867 within the Operational Programme Research and by the Ministry of Education, Youth and Sports of the Czech Republic - DKRVO (RP/CPS/2020/004).

\section{References}

[1] GENT, A.N. (2012). Engineering with Rubber. How to Design Rubber Components, p. 434. Hanser Publications, Cincinnati. USA. ISBN 978-3446-42764-8.

[2] LIMPER, A. (2012). Mixing of rubber compounds, p. 240. Carl Hanser Verlag, Munich. Germany. ISBN 978-3-446-41743-4.

[3] WANG, H., ZHANG, X.P., NIE, H.R., WANG, R.G., HE, A.H. (2019). Multi-block copolymer as reactive multifunctional compatibilizer for NR/BR blends with desired network structures and dynamical properties: Compatibility, co-vulcanization and filler dispersion. In: Composites Part A-Applied Science and Manufacturing, Vol. 116, pp. 197 - 205. Elsevier. England. ISSN 1359-835X.

[4] ERMAN, B., MARK, J.E., ROLLAND, C.M. (2013). The science and technology of rubber, p. 786. Elsevier, Waltham. USA. ISBN 978-0-12394584-6.

[5] ZHANG, P., ZHAO, F., YUAN, Y., SHI, X.Y., ZHAO, S.G. (2010). Network evolution based on general-purpose diene rubbers/sulfur/TBBS system during vulcanization (I). In: Polymer, Vol. 51, No. 1, pp. 257 - 263. Elsevier. England. ISSN: 0032-3861. 
[6] DICK, J. (2014). How to Improve Rubber Compounds: 1800 Experimental Ideas for Problem Solving, p. 407. Hanser Publications, Cincinnati. USA. ISBN-10 : 1569905339.

[7] CHANDRASEKARAN, V.C. (2010). Rubber seals for fluid and bydraulic systems, p. 160. Elsevier, Oxford. England. ISBN 978-0-8155-2075-7.

[8] ECKHOFF, R.K. (2016). Explosion hazards in the process industries, p. 576. Elsevier, Oxford. England. ISBN-13: 978-0128032732.

[9] THOMAS, S., CHAN, C.H., POTHEN, L.A., JOY, J.P., MARIA, H.J. (2014). Natural rubber materials, Volume 2 - Composites and nanocomposites, p. 856. The Royal Society of Chemistry, Cambridge. England. ISBN 978-1-84973-631-2.

[10] HALLEY, P.J., GEORGE, G.A. (2009). Chemorheology of Polymers - From Fundamental Principles to Reactive Processing, p. 454. Cambridge University Press, Cambridge. England. ISBN13: 978-1906985134.

[11] YOON, B., KIM, J.Y., HONG, U., OH, M.K., KIM, M., HAN, S.B., NAM, J.D., SUHR, J. (2020). Dynamic viscoelasticity of silica - filled styrene butadiene rubber/polybutadiene rubber (SBR/BR) elastomer composites. In: Composites Part B-Engineering, Vol. 187, 107865. Elsevier. Oxford. England. ISSN: 1359-8368.

[12] LE, H.H., ABHIJEET, S., ILISCH, S., (2014). The role of linked phospholipids in the rubberfiller interaction in carbon nanotube (CNT) filled natural rubber (NR) composites. In: Polymer, Vol. 55, No. 18, pp. 4738 - 4747. Elsevier. Oxford. England. ISSN: 0032-3861.
[13] COX, R.L. (2012). Engineered Tribological Composites: The Art of Friction Material Development, $\mathrm{p}$. 524. SAE International, London. England. ISBN 9780768073812.

[14] BLAU, P.J. (2001). The significance and use of the friction coefficient. In: Tribology International, Vol. 34, No. 9, pp. 585 - 591. Elsevier. Oxford. England. ISSN: 0301-679X.

[15] RAO, S. (2005). Mechanical Vibrations., pp. 281 - 287. Upper Saddle River, New Jersey. USA. IBSN 978-0132128193.

[16] MORALES, C.A. (2003). Transmissibility concept to control base motion in isolated structures. In: Engineering Structures, Vol. 25, No. 10, pp. 1325 - 1331. Elsevier. Oxford. England. ISSN 0141-0296.

[17] KLIMENDA, F., SOUKUP, J., STERBA, J. (2019). Noise and Vibration Analysis of Conveyor Belt. In: Manufacturing Technology, Vol. 19, No. 4, pp. 604 - 608. J. E. Purkyne University. Usti nad Labem, Czech Republic. ISSN 12132489.

[18] PERSSON, B.N.J., ALBOHR, O., MANCOSU, F., PEVERI, V., SAMOILOV, V., SIVEBAEK, I.M. (2003). On the nature of the static friction, kinetic friction and creep. In: Wear, Vol. 254, No. 9, pp. 835 - 851. Elsevier. Lausanne. Switzerland. ISSN 0043-1648.

[19] BAKOSOVA, D. (2018). Dynamic Mechanical Analysis of Rubber Mixtures Filled by Carbon Nanotubes. In: Manufacturing Technology, Vol. 18, No. 3, pp. 345 - 351. J. E. Purkyne University. Usti nad Labem, Czech Republic. ISSN 12132489. 